\title{
The chromosome cytology of a somatic hybrid petunia
}

\author{
Julia White* and \\ H. Rees
}

Department of Agricultural Botany, University College of Wales, Aberystwyth

The somatic hybrid between Petunia parodii $(2 n=14)$ and $P$. parviflora $(2 n=18)$ is an aneuploid with 31 chromosomes. The missing chromosome was a product of interchange between a large, satellited $P$. parodii chromosome and a medium sized chromosome from $\boldsymbol{P}$. parviflora. Chromosome pairing at meiosis in hybrid pollen mother cells is almost exclusively between strictly homologous chromosomes, i.e. the hybrid behaves as an allotetraploid. The mean bivalent chiasma frequency in the hybrid is achieved in an unusual way, by increase in the bivalent chiasma frequency of $P$. parodii chromosomes relative to that in the parent pollen mother cells, and decrease in the bivalent chiasma frequency of $P$. parviflora chromosomes relative to that in the parent. The distribution of chiasmata in the hybrid also differs from that in the parent. In the $P$. parodii chromosomes there is a very pronounced increase in the frequency of interstitial chiasmata. In respect of both chiasma frequency and distribution the results show that the $\boldsymbol{P}$. parodii and $\boldsymbol{P}$. parviflora chromosomes respond differently to control exercised by the hybrid genotype, in other words control is chromosome-specific.

\section{INTRODUCTION}

The technique of somatic hybridisation, by protoplast fusion followed by regeneration of plants from callus tissue, has allowed hybrids to be made between sexually incompatible plant species. The following account describes the chromosome cytology of one such hybrid, produced from Petunia parodii and $P$. parviflora (Power et al., 1980). A description of the chromosome complements of the parents and the hybrid is included, but the main emphasis is upon their behaviour at meiosis. In this connection we were concerned, above all, with establishing to what extent and in what manner the two complements respond differently and specifically to control exercised upon their behaviour at meiosis by the novel, hybrid genotype.

\section{MATERIAL AND METHODS}

Seeds of $P$. parodii and $P$. parviflora and cuttings of the somatic hybrid were presented to us by Professor Cocking of Nottingham University, to whom we are grateful.

\footnotetext{
* Present address: Department of Biology, University of Lancaster.
}

Preparations of mitotic metaphases were made from root meristems, fixed in alchohol: acetic acid followed by Feulgen staining. Pollen mother cells were stained in aceto-carmine.

DNA estimations. Root tips were fixed in 4 per cent formaldehyde in neutral phosphate buffer for 2 hours, washed in distilled water for 24 hours, re-fixed in acetic: alcohol for 24 hours, hydrolysed in $5 \mathrm{~N} \mathrm{HCl}$ at room temperature, stained in Feulgen solution and scanned under a Vickers M86 Integrating Microdensitometer. Measurements in Allium cepa root tips were used to convert absorption values to picograms.

Dry Mass Measurements. Nuclei were isolated from root tips following immersion in ice-cold 2 per cent formaldehyde in $M / 30$ phosphate buffer for 10 minutes. Scanning was in the Vickers M86 Integrating Microdensitometer. Details of the theory and procedures for calculating the dry mass are given by Barer (1956) and Davies (1958).

\section{RESULTS}

\section{(A) The mitotic complements}

Chromosome size, mass and DNA content. Figs. 1a and $\mathrm{b}$ show that, without exception, the chromosomes of $P$. parodii $(2 n=14)$ are bigger than those 


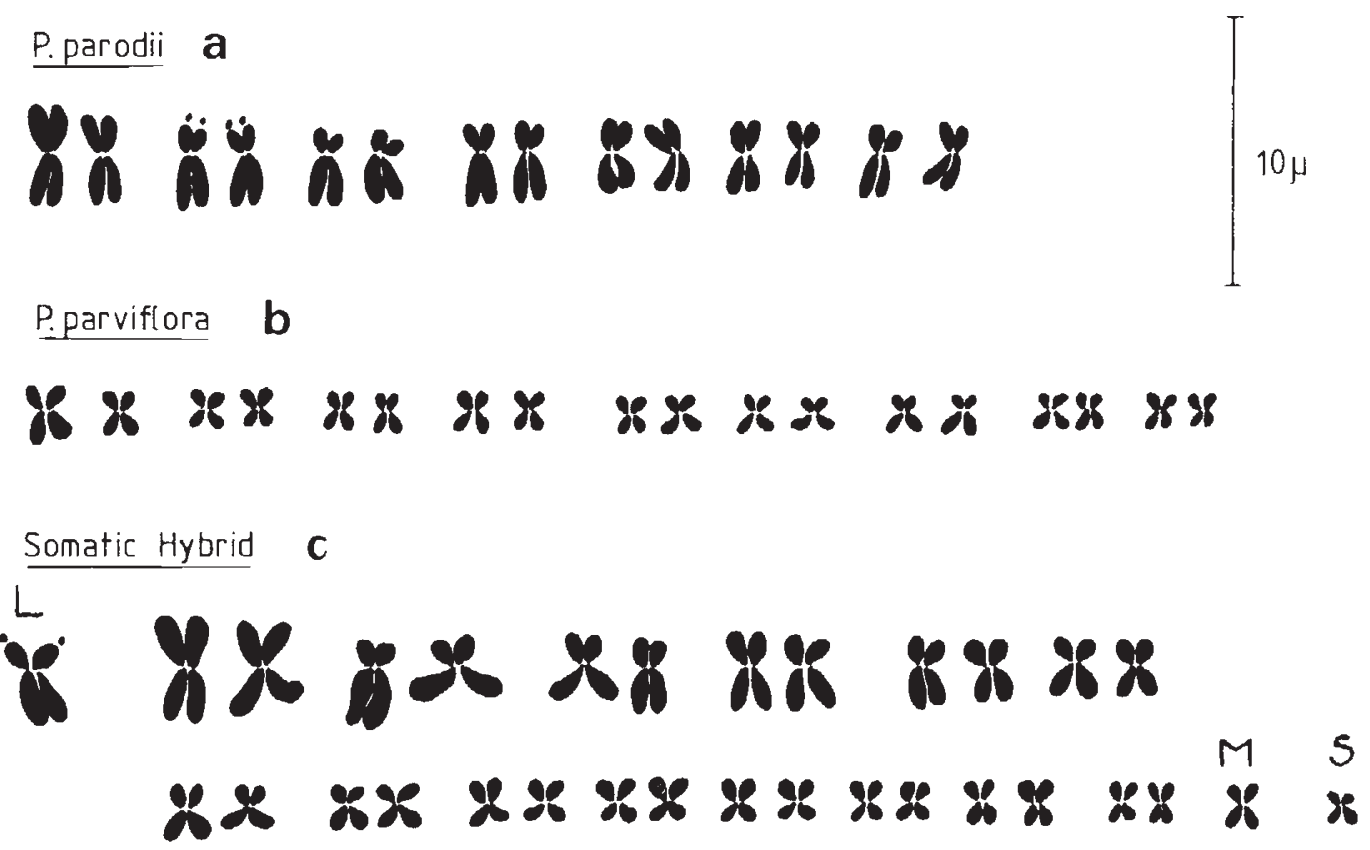

Figure 1 a, $b$ and $c$ are the mitotic complements of $P$. parodii, $P$. parviflora and the somatic hybrid at metaphase. $L, M$ and $\mathrm{S}$ are the three chromsomes without partners.

of $P$. parviflora $(2 n=18)$. The $P$. parodii chromosomes are bigger not because the same amount of chromosome material is distributed among a smaller number. In $P$. parodii the total chromosome volume, the total dry mass and the nuclear DNA content are all substantially greater than in $P$. parviflora (table 1).

Table 1 The total chromosome volume in microns ${ }^{3}$, the $2 C$ : nuclear dry mass in pg. and $2 C$ nuclear DNA amounts (pg.) in the parents.

\begin{tabular}{llll}
\hline & $\begin{array}{l}\text { Total } \\
\text { chromosome } \\
\text { volume }\end{array}$ & $\begin{array}{l}\text { Nuclear } \\
\text { drymass }\end{array}$ & $\begin{array}{l}\text { Nuclear } \\
\text { DNA }\end{array}$ \\
\hline $\begin{array}{llll}\text { P. parodii } \\
P . \text { parviflora }\end{array}$ & $4 \cdot 50$ & 23.8 & 3.0 \\
\hline
\end{tabular}

Means are derived from at least three replicates

The somatic hybrid has 31 chromosomes instead of the expected 32 (fig. 1c). The figure shows but one large, satellited chromosome $(L)$. Its partner is missing. There is, however, a further complication. Two other chromosomes in the hybrid are without partners. One $(S)$ is smaller than any in either of the parental complements. The other $(M)$ is of medium size. These observations may be accounted for by interchange of segments between one of the large, satellited $P$. parodii

chromosomes and a $P$. parviflora chomosome of medium size, followed by loss of one of the interchange products (fig. 2). That the chromosome lost is large and carries a satellite is obvious. That it is the product of interchange rather than the standard satellited chromosome of $P$. parodii is established as follows. Following interchange of the kind depicted in fig. 2 the ratio of long to short arm in
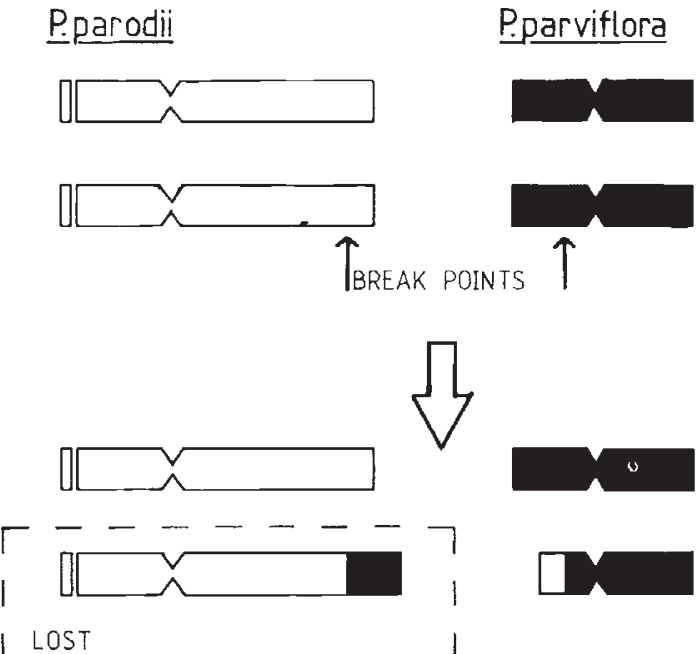

Figure 2 Origin of the novel chromosome complement of the Petunia somatic hybrid by reciprocal interchange, followed by loss of the large interchange product. 
the large interchange product would be increased in comparison with that of the standard, satellited chromosome of $P$. parodii. The average arm ratios, based on measurements in each of five cells, in the satellited chromosome in $P$. parodii and in the hybrid were 2.40 and 2.20 respectively, ratios which did not differ significantly from one another. Further confirmation of the loss of the satellited interchange product comes from observations at meiosis as will be described in a later section.

When the hybrid was first examined the chromosome number was 32 (Power, et al., 1980).

(a)

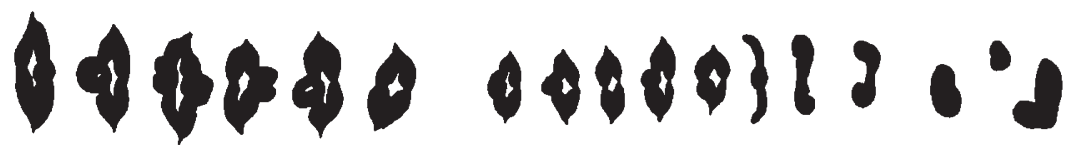

(b)

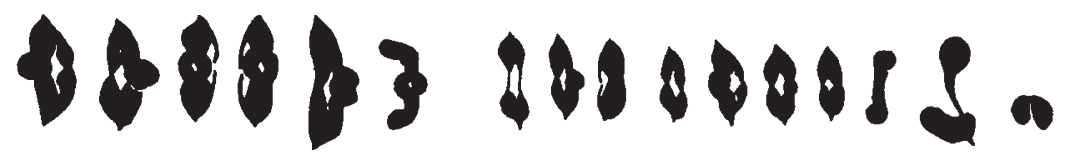

(c) $\cos \{\}$

00008385

(d)
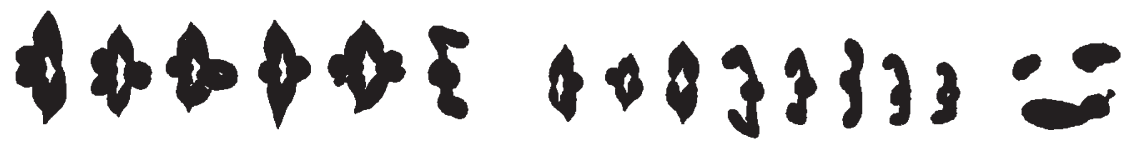

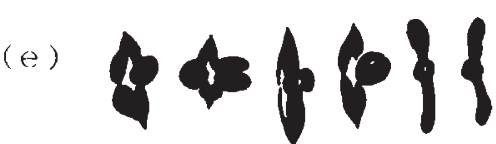

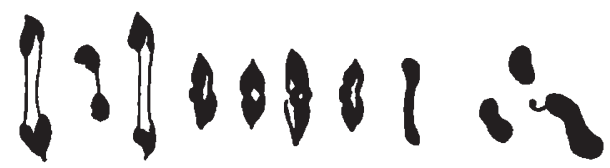

( f )

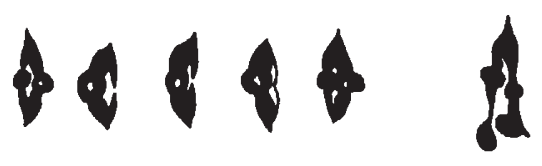

4818393

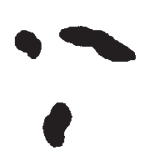

$(\xi)$
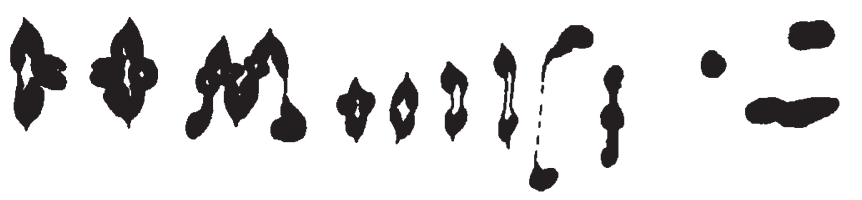

( h )
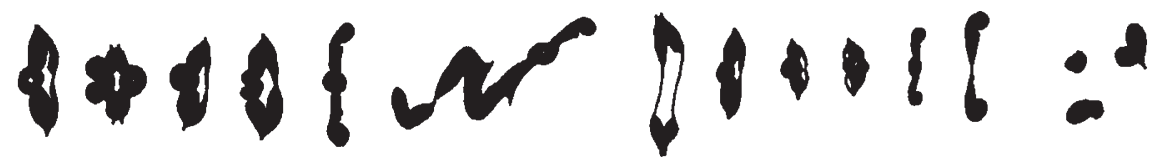

Figure 3 a, c, $\mathrm{d}$ and e are typical hybrid pollen mother cells with three univalents, $L, M$ and $S$. 3b shows an $L / S$ bivalent. Figs. $\mathrm{f}-\mathrm{h}$ pollen mother cells with multivalents (not all chromosomes drawn). 
The interchange coupled with choromosome loss must, therefore, have taken place during propagation, by cuttings, of the somatic hybrid subsequent to regeneration.

\section{(B) Meiosis}

(i) The hybrid. Figs. 3a, c, d and e show typical pollen mother cells at first metaphase, with 14 bivalents and three univalents. All bivalents are symmetrical which indicates that pairing is between strictly homologous as distinct from homoeologous chromosomes, that is to say typical of a classical allotetraploid. The six large $P$. parodii bivalents are readily distinguishable from the eight smaller bivalents of $P$. parviflora.

The three univalents are the $L, M$ and $S$ chromosomes which were identified at mitosis. None of these three pairs with other chromosomes of the complement, which is in keeping with the "interchange and loss" hypothesis presented in fig. 2. Complete confirmation of the hypothesis comes from the following observations. In about 10 per cent of pollen mother cells there are chiasmate associations between $L$ and $S$ (e.g. fig. 1b) or between $M$ and $S$, never between $L$ and $M$. Such pairing is compatible only with loss of the large satellited product of interchange, not with the loss of the standard satellited chromosome of $P$. parodii (fig. 4). Univalents other than $L, M$ and $S$ are found in about 6 per cent of pollen mother cells. They result from asynapsis or desynapsis.

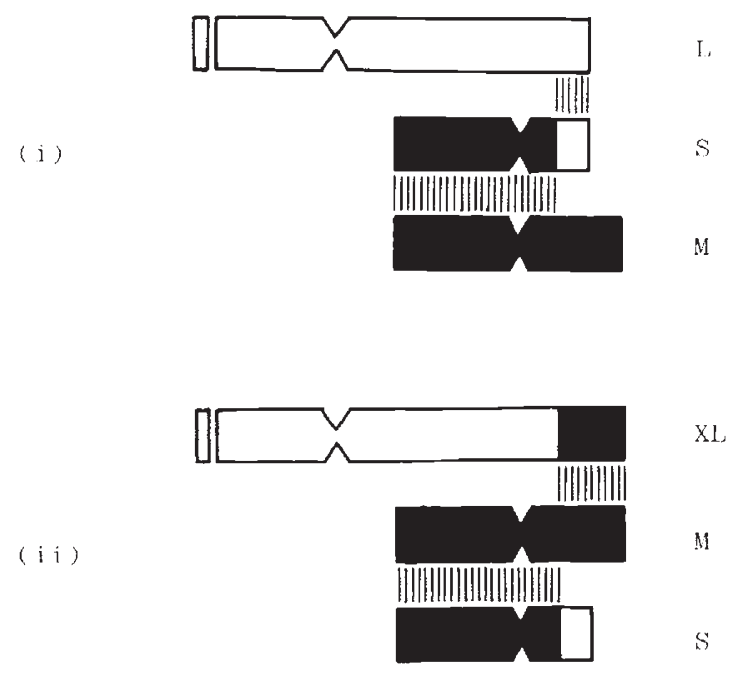

Figure 4 Pairing possibilities assuming loss of the large interchange product (i) and of the standard $P$. parodii satellited chromosome (ii).
About 20 per cent of pollen mother cells show multivalents at first metaphase (figs. $3 f-h$ ). They incorporate both large, $P$. parodii and small, $P$. parviflora chromosomes. They may be accounted for in one of two ways, either by some degree of homoeologous pairing or by further interchanges. Because some of the configurations are chains-offive (fig. $3 \mathrm{~h}$ ) the latter is the more probable explanation.

As a consequence of the aneuploid nature of the hybrid, of interchange, and of the formation of multivalents and univalents we should expect considerable inviability of pollen. Estimates based on "stainability" ranged from 80 to 90 per cent. We have no information about "female" meiosis or about the viability of female gametes.

(ii) Hybrid versus Parents. Comparisons between the behaviour of chromosomes in parent and hybrid pollen mother cells. embraced two characters, the frequency of chiasmata and the distribution of chiasmata within bivalents.

In both seasons the chiasma frequency per bivalent is higher in the $P$. parviflora parent than the $P$. parodii parent. In both seasons the mean bivalent chiasma frequency in the hybrid is very similar to that of the P. parviflora parent (table 2). In themselves these results are not exceptional. The difference between the parents may be accounted for by genotypic control. On the same

Table 2 The mean chiasma frequencies in $P$. parodii and $P$. parviflora bivalents in parent and hybrid pollen mother cells

\begin{tabular}{|c|c|c|c|c|}
\hline & \multicolumn{2}{|c|}{ In the parents } & \multicolumn{2}{|c|}{ In the somatic hybrid } \\
\hline & P. parviflora & P. parodii & P. parviflora & P. parodii \\
\hline \multirow[t]{5}{*}{1981} & $1 \cdot 86$ & 1.56 & $1 \cdot 71$ & $2 \cdot 00$ \\
\hline & $1 \cdot 88$ & 1.41 & 1.75 & $2 \cdot 05$ \\
\hline & $1 \cdot 79$ & 1.49 & $1 \cdot 70$ & $2 \cdot 23$ \\
\hline & $1 \cdot 83$ & 1.44 & 1.58 & $2 \cdot 11$ \\
\hline & $1 \cdot 80$ & $1 \cdot 49$ & $1 \cdot 50$ & $1 \cdot 96$ \\
\hline \multirow{2}{*}{$\begin{array}{l}\text { Means } \\
\text { Overall } \\
\text { mean }\end{array}$} & 1.83 & $1 \cdot 48$ & 1.65 & $2 \cdot 07$ \\
\hline & $1 \cdot 83$ & 1.48 & \multicolumn{2}{|l|}{1.86} \\
\hline \multirow[t]{5}{*}{1982} & $1 \cdot 76$ & $1 \cdot 34$ & 1.48 & $1 \cdot 90$ \\
\hline & 1.74 & 1.39 & $1 \cdot 70$ & $1 \cdot 80$ \\
\hline & 1.73 & $1 \cdot 31$ & $1 \cdot 70$ & 1.93 \\
\hline & $1 \cdot 77$ & 1.44 & 1.68 & $1 \cdot 73$ \\
\hline & $1 \cdot 78$ & 1.43 & $1 \cdot 65$ & 1.93 \\
\hline \multirow{2}{*}{$\begin{array}{l}\text { Means } \\
\text { Overall } \\
\text { mean }\end{array}$} & $1 \cdot 76$ & $1 \cdot 38$ & $1 \cdot 64$ & $1 \cdot 86$ \\
\hline & $1 \cdot 76$ & $1 \cdot 38$ & \multicolumn{2}{|l|}{$1 \cdot 75$} \\
\hline
\end{tabular}

Mcans were derived from 20 pollen mother cells in each parent plant and an average of 6 pollen mother cells in each hybrid "plant". 
basis, the high chiasma frequency in the hybrid could be interpreted on the simple assumption that genes responsible for the high chiasma frequency in $P$. parviflora were "dominant" in expression within the hybrid pollen mother cells. It is when we come to consider the chiasma frequencies in the separate complements in the hybrid that the results command particular interest.

Table 2 shows that the high overall mean chiasma frequency in the hybrid is achieved by a very considerable increase within the $P$. parodii complement, as compared with the mean of the same complement in the parent, and a substantial decrease within the $P$. parviflora complement relative to that of the same chromosomes in the parent. The situation is reflected in graphic form in fig. 5 .

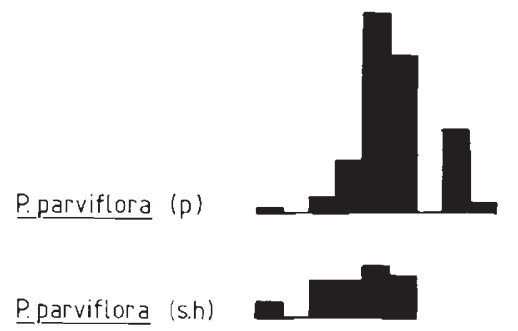

Somatic hybrid
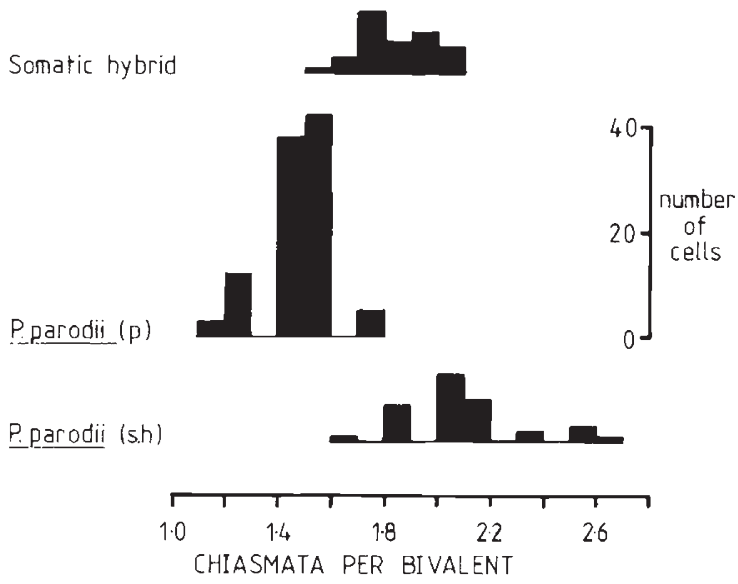

Figure 5 Chiasma frequencies in bivalents of $P$. parodii and $P$. parviflora in pollen mother cells of the parents $(\mathrm{p})$ and the hybrid (s.h.) in 1981.

The evidence points clearly to a differential response of $P$. parodii and $P$. parviflora chromosomes to control exercised by the hybrid genotype. This is confirmed by an analysis of variance (table 4) of the data. The item for interaction between complements and background (i.e. hybrid versus parental) is highly significant $(P=<0 \cdot 001)$.

The analysis of variance also showed a significant difference in the mean bivalent chiasma frequency between years $(P=<0.001)$. Of more interest, however, was a significant interaction between the chromosome complements and years $(P=<0 \cdot 05)$. Not only do the chromosomes of $P$. parodii and $P$. parviflora respond differently to control by the genotype, parental and hybrid, but, also, to control imposed by the environment.

For the $P$. parodii complement, in the parent the vast majority of chiasmata are located distally (fig. 6) and there is no significant change in distribution between seasons (table 3 ). Diplotene configurations show that these distal chiasmata at first metaphase in $P$. parodii, and the same is true of $P$. parviflora, are not due to "terminalisation".
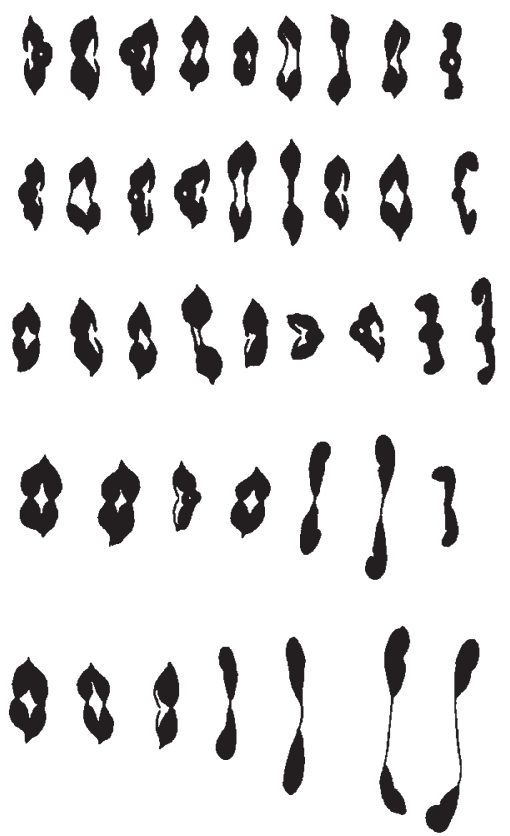

( f )

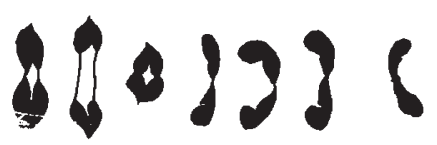

Figure 6 Bivalents of $P$. parviflora $(\mathrm{a}-\mathrm{c})$ and $P$. parodii $(\mathrm{d}-\mathrm{f}$ ) in parental pollen mother cells at first metaphase meiosis.

In the hybrid pollen mother cells, in both seasons, the same $P$. parodii bivalents have mainly interstitial chiasmata (table 3 ). The change is dramatic and chi square tests confirm that the change is highly significant, with a probability of less than 0.001 for both rods and rings. 
Table 3 The distribution of interstitial and distal chiasmata in $P$. parodii and $P$. parviflora bivalents in parent and hybrid pollen mother cells. (Bivalents chosen at random up to a total of 50 )

$$
\text { Rod bivalents Ring bivalents }
$$

\begin{tabular}{llcccccc}
1981 & & Interstitial & Distal & Total & Interstitial & Distal & Total \\
\hline P. parodii & Parent & 13 & 37 & 50 & 0 & 50 & 50 \\
P. parviflora & Hybrid & 33 & 17 & 50 & 34 & 16 & 50 \\
& Parent & 10 & 40 & 50 & 6 & 44 & 50 \\
& Hybrid & 15 & 35 & 50 & 11 & 39 & 50 \\
\hline P. parodii & & & & & & & \\
P. parviflora & Parent & 44 & 156 & 200 & 2 & 98 & 100 \\
& Hybrid & 23 & 7 & 30 & 91 & 9 & 100 \\
& Parent & 69 & 31 & 100 & 28 & 72 & 100 \\
\hline
\end{tabular}

Table 4 Analysis of variance of mean chiasma frequency per bivalent in parents and somatic hybrid in 1981 and 1982

\begin{tabular}{|c|c|c|c|c|c|}
\hline Source of variation & SS & df & M.S. & V.R. & $\mathrm{P}$ \\
\hline $\begin{array}{l}\text { Total } \\
\text { combination }\end{array}$ & $\begin{array}{l}1.8795 \\
1.6917\end{array}$ & $\begin{array}{r}39 \\
7\end{array}$ & 0.2416 & $40 \cdot 9492$ & $<0.001$ \\
\hline (i) Difference between years (1981 and 1982) & 0.0950 & 1 & 0.0950 & $16 \cdot 1017$ & $<0.001$ \\
\hline (ii) Difference between backgrounds (both genomes) & $0 \cdot 3705$ & 1 & $0 \cdot 3705$ & $62 \cdot 7966$ & $<0.001$ \\
\hline (iii) Difference between genomes (in both backgrounds) & $0 \cdot 0050$ & 1 & 0.0050 & $0 \cdot 8475$ & N.S. \\
\hline (iv) Interaction between years and background & 0.0013 & 1 & $0 \cdot 0013$ & $0 \cdot 2203$ & N.S. \\
\hline (v) Interaction between years and individual genomes & 0.0319 & 1 & 0.0319 & $5 \cdot 4068$ & $<0.05$ \\
\hline (vi) Interaction between background and individual genomes & $1 \cdot 1662$ & 1 & $1 \cdot 1662$ & $197 \cdot 6610$ & $<0.001$ \\
\hline (vii) Interaction between years background and genomes & 0.0216 & 1 & 0.0216 & $3 \cdot 6610$ & N.S. \\
\hline Error & $0 \cdot 1878$ & 32 & 0.0059 & & \\
\hline
\end{tabular}

It will be recalled that the chiasma frequency of $P$. parodii chromosomes was higher in the hybrid than in the parent (tables 2 and 4 ). The question arises as to whether the increase in interstitial chiasmata in the hybrid is simply a consequence of this increase in frequency (cf. Rees and Dale, 1974). All the rod bivalents scored in both parents and hybrid had one chiasma only yet, as is clear from table 3 , the location of the chiasmata was very different in parent and hybrid. This in itself establishes that the redistribution of chiasmata is, at the very least, largely independent of the chiasma frequency.

For $P$. parviflora complement, in the parent most chiasmata are located distally, although to a lesser degree than in $P$. parodii (fig. 6 and table 3 ). In contrast to $P$. parodii the relative frequencies of interstitial and distal chiasmata in the parent species vary significantly between years, both for rods $(P=<0.001)$ and rings $(P=<0.05)$.

In the hybrid the frequency of interstitial chiasmata within $P$. parviflora bivalents in 1981 was, as for $P$. parodii bivalents, higher than in the parent but not significantly so. In 1982 ( $c f$. $P$. parodii) there are significantly fewer interstitial chiasmata in the rod bivalents $(P=<0.001)$, there being no change in rings.

Considering the results from the $P$. parodii and $P$. parviflora chromosomes together what is abundantly clear is that, as with the chiasma frequency, the different complements respond in different and specific fashion to control by both genotype and environment. We wish to emphasise in particular that within the same, hybrid nucleus the control exercised is specific to particular chromosomes within that nucleus.

\section{DISCUSSION}

To the cytologist this somatic hybrid has useful and attractive features, even though the chromosomes are small and difficult to handle. Above all, the parental complements are distinguishable. For this reason it was possible to establish that certain structural changes involved chromosomes from both complements; also to identify the chromosome lost from the aneuploid, hybrid complement. Structural and numerical chromosome changes are by no means uncommon following regeneration 
from callus and cell cultures (e.g., Karp and Maddock, 1984). The causes of such chromosome instability are not clear. What is clear in this case is that the instability was manifested during propagation of the mature plant, as distinct from the propagation of cells during callus formation.

The capacity for identifying the separate complements was particulary useful at meiosis. It was possible, in the first place, to ascertain that chromosome pairing was characteristic of an allopolyploid. Second, it could be demonstrated that the two chromosome complements were affected differently by control exercised by the hybrid genotype, in respect both of the frequency and distribution of chiasmata. The response to genotype, in other words, was specific, as indeed was the response to seasonal change, even in the same, hybrid cell environment.

Surprisingly, investigations into chromosomespecific control have been few. What evidence there is from such investigation, however, is convincing and, at the same time, of compelling interest. That different chromosomes within the same nucleus respond differently to the same overall control implies that particular chromosomes within a nucleus may show very different patterns of behaviour. When the control impinges upon the formation of chiasmata, their frequency and distribution, the rate of release of variability by crossing over will vary from one chromosome to the other, from one chromosome segment to another, from one gene cluster to another. In this respect the results from this hybrid Petunia confirm and reinforce the observations and conclusions of Parker (1975) and of Tease and Jones (1976) who demonstrated chromosome-specific control of chiasma formation in diploid populations of Crepis capillaris.

\section{REFERENCES}

BARER, R. (1956). The Interference Microscope in Quantitative Cytology. Suppl. to 2nd Edition. The Baker Interference Microscope.

DAVIES, H. G. (1958). The determination of mass and concentration by microscope interferometry. In General Cytochemical Methods; vol. 1. Academic Press.

KARP, A. AND MADDOCK, M. E. (1984). Chromosome variation in wheat plants regenerated from cultured immature embryos. Theor. Appl. Genet., 67, 249-255.

PARKER, J. S. (1975). Chromosome-specific control of chiasma formation. Chromosoma, 49, 391-406.

POWER, J. B., BERRY, S. F., CHAPMAN, J. V. AND COCKING, E. C. (1980). Somatic hybridization of sexually incompatible petunias: Petunia parodii, Petunia parviflora. Theor. Appl. Genet. 57, 1-4.

REES, H. AND DALE, P. J. (1974). Chiasmata and variability in Lolium and Festuca populations. Chromosoma, 47, 335351.

TEASE, C. AND JONES, G. H. (1976). Chromosome-specific control of chiasma formation in Crepis capillaris. Chromosoma, $57,33-49$. 